\title{
Aerosol drug delivery to tracheotomized patients with COVID-19: Pragmatic suggestions for clinicians
}

\author{
Arzu Ari, PhD, RRT, PT, CPFT, FAARC, FCCP, James B. Fink, PhD, RRT, FAARC, FCCP
}

\begin{abstract}
A. Ari, JB. Fink. Aerosol drug delivery to tracheotomized patients with COVID-19: Pragmatic suggestions for clinicians. Can J Respir Ther 2021;57:49-52. doi: 10.29390/cjrt-2020-054.

Because of the wide and rapid spread of severe acute respiratory syndrome coronavirus 2 (SARS-CoV-2), the number of hospitalized patients with coronavirus disease 2019 (COVID-19) has rapidly increased medically complex and resource-intensive treatment requirements in health care settings. Although tracheostomy is frequently needed for critically ill patients requiring extended mechanical ventilation, it has been described as an aerosol-generating procedure that puts health care professionals at an increased risk of viral transmission. In addition, the delivery of aerosolized medications to this patient population has become controversial because of concerns on the transmission of SARS-CoV-2 via droplets. Although aerosol therapy in spontaneously breathing patients with COVID-19 was described in recent publications, innovations in aerosol drug delivery to COVID-19 patients with tracheostomy have not been presented. Therefore, empirically based guidance on how to deliver aerosols safely and effectively to tracheotomized patients with COVID-19 is still lacking. This paper provides recommendations and rationales for device selection, interface selection, delivery techniques, and infection control based on the evolving body of literature.
\end{abstract}

Key Words: nebulizers; metered-dose inhalers; tracheostomy; SARS-CoV-2

\section{INTRODUCTION}

The rapid spread of severe acute respiratory syndrome coronavirus 2 (SARS-CoV-2) has impacted the number of hospitalized patients with coronavirus disease 2019 (COVID-19) and increased the volume of medically complex and resource-intensive treatment requirements in acute care settings. Because SARS-COV-2 is transmitted by droplets [1-5], there has been a move to avoid aerosol-generating procedures (AGPs) that put health care professionals (HCPs) at an increased risk of viral transmission. Many AGPs were initially identified during and subsequent to the SARS outbreak, often without supporting evidence. Since tracheostomy has been described as an AGP, the use of tracheostomy in critically ill patients with COVID-19 has become controversial, resulting in a reluctance to perform this procedure when indicated [6]. Tracheostomy is indicated in critically ill patients requiring extended mechanical ventilation, with COVID-19 patients often requiring three or more weeks of ventilation. While delaying the insertion of tracheostomy to this patient population might hypothetically decrease the risk of viral transmission, it will likely increase the incidence of established complications and morbidity associated with extended endotracheal intubation. A recently published guideline recommends that the timing of tracheostomy should be based on potential risks and benefits for the patient, available resources in health care settings, as well as risks to HCPs, caregivers, and other patients [7]. The surgical placement of a tracheotomy can involve potential infectious bioaerosols expelled at the site of surgery with cough and the spray of secretions. Tracheostomies for mechanically ventilated patients requiring extended ventilation are elective procedures. Consequently, the risks of aerosol transmission may be readily mitigated by performing the procedure in a wellventilated procedure room or operating theater, with a high level of personal protective equipment (PPE) for HCPs in the vicinity. For instance, HCPs should wear respirators like the filtering face piece or
N95 or equivalent that filter $>94 \%$ of particles 0.3 microns or larger rather than the less protective surgical masks. In addition, aprons, double gloves, and goggles/face shields should be donned every time HCPs deliver aerosolized medications to tracheotomized patients with COVID-19. HCPs should also adhere to hand hygiene before and after the treatment by using an alcohol-based hand sanitizer or washing hands with soap and water.

Although aerosol therapy in spontaneously breathing and mechanically ventilated patients with COVID-19 was described in recent publications $[8,9]$, guidance on how to deliver aerosols safely and effectively to tracheotomized patients with COVID-19 is still lacking. The delivery of medical aerosols to this patient population has led to hot debates because SARS-CoV-2 spreads via droplets that remain viable and infectious for hours [4]. There is no evidence to support that inhaled medical aerosol becomes contaminated while in the lung before exhalation [10]. The greater risk is the exhalation of patient-generated bioaerosols with pathogens and the medical aerosols released as fugitive emissions that have not been inhaled by the patient and released into the environment during expiration [11]. The dispersion distance of fugitive emissions and patient-generated bioaerosols vary depending on specific AGPs used for patients. While AGPs such as intubation, open suctioning, or bronchoscopy increase bioaerosol production, there is no evidence to suggest that nebulizers or inhalers increase the generation of bioaerosols by the patient.

On the contrary, nebulized isotonic saline decreases exhaled bioaerosol generation by $72 \%$ for $6 \mathrm{~h}$ [12]. A retrospective study of a pooled analysis of risk with various AGPs showed that HCPs had a far greater risk of infection with intubation and noninvasive ventilation than nebulizers [6]. This paper provides recommendations and rationales for device selection, interface selection, delivery techniques, and infection control based on the evolving body of literature (Table 1).

Department of Respiratory Care, Texas State University, College of Health Professions, Round Rock, TX, USA

Correspondence: Arzu Ari, Department of Respiratory Care, College of Health Professions, Texas State University, 200 Bobcat Way, Willow Hall, Suite\# 214

Round Rock, Texas, 78665,E-mail: arzuari@txstate.edu

Published online at https://www.cjrt.ca on 30 April 2021 
TABLE 1

Pragmatic recommendations and rationales for device selection, interface selection, delivery techniques, and infection control for aerosol drug delivery to tracheotomized patients with COVID-19

\begin{tabular}{|c|c|c|}
\hline & Recommendations & Rationales \\
\hline $\begin{array}{l}\text { Device } \\
\text { selection }\end{array}$ & $\begin{array}{l}\text { - Avoid using pMDIs or jet nebulizers for aerosol drug delivery } \\
\text { to tracheotomized patients with COVID- } 19 \text {. } \\
\text { - Prefer using mesh nebulizers for aerosol delivery to this } \\
\text { patient population in the era of COVID-19. } \\
\text { - In the absence of mesh nebulizers, use jet nebulizers with } \\
\text { a valved T-piece. }\end{array}$ & $\begin{array}{l}\text { - Breaking the circuit for device placement will increase exposure to bioaerosols } \\
\text { and viral transmission. } \\
\text { - Mesh nebulizers don't require breaking the circuit for device placement and can } \\
\text { stay in line for up to } 28 \text { days. } \\
\text { - The reservoir of the nebulizer is separated from the circuit and eliminates } \\
\text { device contamination }\end{array}$ \\
\hline $\begin{array}{l}\text { Interface } \\
\text { selection }\end{array}$ & $\begin{array}{l}\text { - Avoid using the tracheostomy mask for aerosol therapy to } \\
\text { patients with tracheostomy } \\
\text { - Prefer using a T-piece for aerosol delivery to tracheotomized } \\
\text { patients with COVID-19. }\end{array}$ & $\begin{array}{l}\text { - The design of the tracheostomy mask increases the dispersion of exhaled air } \\
\text { and infectious aerosols due to the open aperture and loose-fit. } \\
\text { - The use of a T-piece with an expiratory filter will decrease exhaled air } \\
\text { dispersion and viral transmission. }\end{array}$ \\
\hline $\begin{array}{l}\text { Delivery } \\
\text { technique }\end{array}$ & $\begin{array}{l}\text { - Use an unassisted technique to deliver aerosols to the patient. } \\
\text { - Do not use the assisted technique unless a filter is attached } \\
\text { to the expiratory port of the manual resuscitation bag. }\end{array}$ & $\begin{array}{l}\text { - Through an expiratory filter, it is possible to keep the circuit intact during therapy. } \\
\text { - Exhaled air dispersion and viral transmission will be a problem with the } \\
\text { assisted technique if there is no filter placed on the expiratory port of the } \\
\text { manual resuscitation bag. }\end{array}$ \\
\hline $\begin{array}{l}\text { Infection } \\
\text { control }\end{array}$ & $\begin{array}{l}\text { - Use personal protective equipment during aerosol } \\
\text { therapy [8-10]. } \\
\text { - Isolate patients and administer aerosols in negative pressure } \\
\text { rooms [8-10]. } \\
\text { - Attach a HEPA filter to the expiratory limb of the circuit in } \\
\text { ventilator-dependent patients with COVID-19 [8-10]. }\end{array}$ & $\begin{array}{l}\text { - It is essential to assume all patients may be infected and protect healthcare } \\
\text { professionals from viral exposure during the assessment, treatment, and } \\
\text { monitoring of patients for aerosol drug delivery [8-10]. } \\
\text { - Isolating patients and administering aerosols in negative pressure rooms are } \\
\text { vital for infection control and prevention [8-10]. } \\
\text { - It will eliminate secondhand aerosol exposure and the transmission of } \\
\text { infectious droplet nuclei through the ventilators [8-10]. }\end{array}$ \\
\hline
\end{tabular}

Device selection

Device selection for tracheotomized patients with COVID-19 should be based on the severity of the patient's clinical condition [8, 13]. For instance, in ventilator-dependent patients, mesh nebulizers should be considered for aerosol delivery to keep the circuit intact. Clinicians can place the mesh nebulizer before the humidifier and use it for up to 28 days in ventilator-dependent patients. The use of pressurized metereddose inhalers (pMDIs) or jet nebulizers in ventilator-dependent patients requires "breaking" the circuit for device placement and expose HCPs bioaerosols that occur with explosive depressurization of the circuit. The design of the mesh nebulizer keeps the reservoir isolated and decreases contamination from the patient and contaminated fluids in the ventilator circuit.

Although nebulizers and pMDIs can be used in spontaneously breathing patients with tracheostomy, deciding which device to use requires careful patient evaluation. It is also important to avoid generating cough or airway irritation during device placement. Attaching the pMDI with a valved-holding chamber (VHC) to tracheostomy may cause cough or airway irritation that increases the risk of exposure to bioaerosols and viral transmission. Jet nebulizers operate with an external gas flow that increases exhaled air dispersion during the treatment of spontaneously breathing patients with COVID-19. In contrast, mesh nebulizers operate electronically and can be kept in the circuit of the high flow oxygen delivery system (Figure 1) or ventilator for up to 28 days. The mesh separating the reservoir from the circuit allows adding the drug to the nebulizer without breaking the circuit for repetitive doses of aerosol therapy. The reservoir cap of the mesh nebulizer should be closed after inserting medication to reduce the risk of device contamination during treatment.

The delivery efficiency of pMDIs with a VHC may be sufficient for some medications [14]. Since a greater nominal dose may be administered with nebulizers, they may be a better option for critically ill tracheotomized patients with COVID-19 who require a larger inhaled dose. Clinicians should be aware of several precautions to minimize exhaled air dispersion and viral transmission when using nebulizers. For instance, the placement of a bacterial viral filter to the exhalation tubing connected to the nebulizer via a T-piece (Figure 1) will reduce exhaled air dispersion and viral transmission. High-efficiency particulate air (HEPA) filters are $99.97 \%$ efficient at capturing humangenerated viral particles associated with SARS-CoV-2 and should be

\section{FIGURE 1}

The set up of the mesh nebulizer with the high flow oxygen delivery system for the treatment of spontaneously breathing tracheotomized patients with COVID-19.

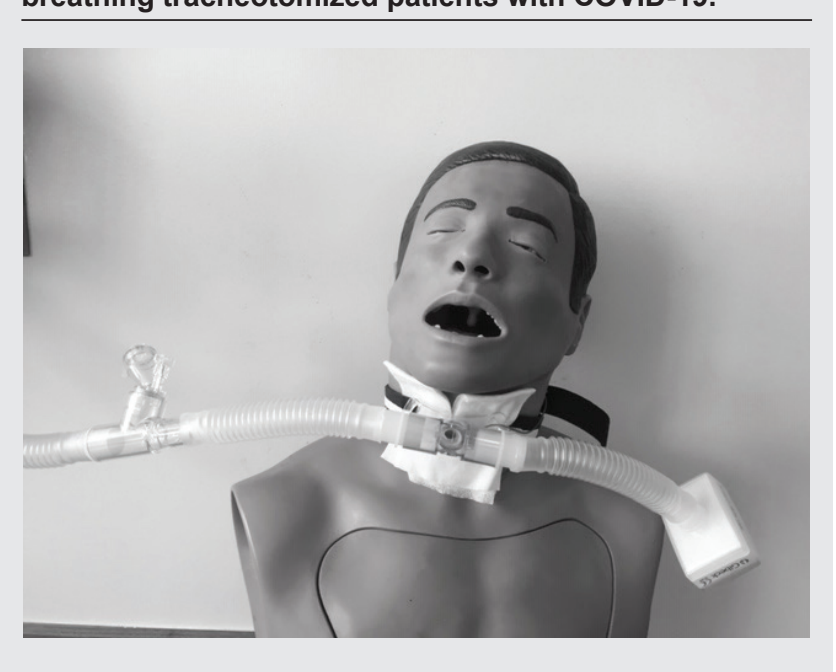

preferred in this patient population $[2,15]$. However, HCPs will need to determine appropriate adaptors to attach filters to the nebulizer $[8,13]$. Also, the placement of a surgical mask on the face of spontaneously breathing patients with open fenestrated tracheostomy tube may reduce the dispersion of exhaled bioaerosols in spontaneously breathing patients with tracheostomy. If the patient is ventilator-dependent, it is important to attach HEPA filters to the expiratory limb of the ventilator circuit because exhaled particles less than 2 micrometers do not deposit via sedimentation or inertial impaction. Since they remain in the air for hours, they increase the risk for viral transmission. In our previous research, we found that the amount of aerosol collected at the exhaust outlet of the ventilator circuit without an expiratory filter was 160 -fold greater than the ventilator with the expiratory filter [16]. 
Therefore, HCPs should attach a HEPA filter to the expiratory limb of the circuit to decrease the transmission of infectious droplets.

\section{Interface selection}

Nebulizers are usually combined with the tracheostomy mask/collar, or the T-piece. According to previous studies, aerosol drug delivery with the T-piece is greater than the tracheostomy mask [14, 17]. Also, the tracheostomy mask design increases the dispersion of exhaled air and infectious aerosols due to the open aperture and loose fit, whereas the T-piece can be used with an expiratory filter to reduce the dispersion of potentially infectious aerosols. Therefore, T-piece should be preferred to deliver aerosolized medication to tracheotomized patients with COVID-19.

\section{Delivery technique}

Assisted and unassisted techniques are used for aerosol delivery to spontaneously breathing patients with tracheostomy. In the assisted technique, a manual resuscitation bag is connected to an aerosol device, and a clinician helps deliver aerosols to the patient by squeezing the flexible bag. In contrast, aerosols are delivered to the patient directly with an aerosol device in the unassisted technique [18]. Using assisted technique is not recommended in this global pandemic unless a bacteria/viral filter is placed between the nebulizer and the manual resuscitation bag. These filters should be changed at regular intervals, based on the amount of aerosol administered, to avoid increased resistance through the filter and increased work of breathing. With standard treatments of 4 doses daily change should be sufficient.

\section{Infection control and prevention}

COVID-19 is extremely transmissible. Since contaminated aerosols may expose HCPs to the virus, poor compliance with infection control and prevention may cause occupationally acquired infection [19]. Therefore, it is imperative to assume all patients may be infected and use PPE during the assessment, treatment, and monitoring of tracheotomized patients with COVID-19. Because of the global shortage of respirators, careful management of the supply chain for PPE and other critical care supplies is needed in health care settings.

Aerosol drug delivery to spontaneously breathing tracheotomized patients with COVID-19 is a high-risk procedure if it is not done correctly. Therefore, patients should be isolated, and clinicians should administer aerosolized medications in negative pressure rooms. Recently, many health care institutions reached maximum capacity with patient demand exceeding negative pressure rooms available for the care of tracheotomized patients with COVID-19. In this case, HCPs may consider using extractor tents with HEPA filters when delivering aerosolized medications to this patient population. Previous research showed that proprietary HEPA filtering extractor tents are efficacious in preventing airborne infection during aerosol therapy with nebulizers [20]. Another option is to use a portable negative pressure hood with HEPA filtration [21] or air purifiers with HEPA filters [22]. Although these studies show decreases in the dispersion of exhaled aerosols, more research is needed to understand their impact on reducing the incidence of viral transmission and infection. Surgical masks can be used in patients with fenestrated tracheostomy tubes to prevent viral transmission. Since exhaled particles from ventilator-dependent patients are less than $2 \mu \mathrm{m}$ and remain in the air, it is crucial to place a HEPA filter in the expiratory limb of the circuit during mechanical ventilation to eliminate secondhand aerosol exposure and the transmission of infectious droplet nuclei through the ventilators [16].

\section{CONCLUSION}

Our primary focus is to ensure the well-being of patients and HCPs by providing required care and minimizing the risk of viral exposure and transmission. This paper provides background, considerations, and recommendations for device selection, interface selection, and delivery techniques based on the evolving body of literature. While direct evidence on aerosol delivery to tracheostomized patients with
COVID-19 is limited, high-quality research is warranted and will be key to the safe and effective delivery of aerosolized medications to tracheotomized patients with COVID-19.

\section{DISCLOSURES}

\section{Competing interest}

Dr. Ari discloses relationships with Aerogen Ltd and Philips Healthcare. Dr. Fink is Chief Science Officer of Aerogen Pharma.

\section{Funding}

No funding was obtained in the preparation of this Innovation in Practice article.

\section{Authors' contributions}

Dr. Ari conceived of the idea, performed the literature search and drafted the article. Dr. Fink provided critical revisions on the manuscript. All authors reviewed, revised, and approved the paper before submission.

\section{Ethics approval}

Not applicable.

\section{REFERENCES}

1. Prather KA, Wang CC, Schooley RT. Reducing transmission of SARSCoV-2. Science 2020; 368:1422-4. doi: 10.1126/science.abc6197.

2. Centers for Disease Control and Prevention. Scientific brief: SARSCoV-2 and potential airborne transmission. 2020: Available at: https://www.cdc.gov/coronavirus/2019-ncov/more/scientific-brief-sars-cov-2.html.

3. World Health Organization. Coronavirus disease (COVID-19): how is it transmitted? 2020: Available at: https://www.who.int/news-room/q-adetail/coronavirus-disease-covid-19-how-is-it-transmitted.

4. Van Doremalen N, Bushmaker T, Morris D, et al. Aerosol and surface stability of SARS-CoV-2 as compared with SARS-CoV-1. New Engl J Med 2020;NEJMc2004973. doi: 10.1101/2020.03.09.20033217.

5. Santarpia JL, Rivera DN, Herrera VL, et al. Aerosol and surface contamination of SARS-CoV-2 observed in quarantine and isolation care. Sci Rep 2020;10:12732. doi: 10.1038/s41598-020-69286-3.

6. Tran K, Cimon K, Severn M, Pessoa-Silva C, Conly J. Aerosol generating procedures and risk of transmission of acute respiratory infections to healthcare workers: a systematic review. PLoS One 2012;7:e35797. doi: 10.1371/journal.pone.0035797.

7. McGrath BA, Brenner MJ, Warrillow SJ, et al. Tracheostomy in the COVID-19 era: global and multidisciplinary guidance. Lancet Respir Med 2020;8:717-25. doi: 10.1016/S2213-2600(20)30230-7.

8. Ari A. Practical strategies for a safe and effective delivery of aerosolized medications to patients with COVID-19. Respir Med 2020;167:105987. doi: $10.1016 /$ j.rmed.2020.105987.

9. Ari A. Use of aerosolised medications at home for COVID-19. Lancet Respir Med 2020;8:754-6. doi: 10.1016/S2213-2600(20)30270-8.

10. Fink J, Ehrmann S, Li J, et al. Reducing aerosol-related risk of transmission in the era of COVID-19: an interim guidance endorsed by the international society of aerosols in medicine. J Aerosol Med Pulm Drug Deliv 2020. doi: $10.1089 /$ jamp.2020.1615.

11. Saeed H, Mohsen M, Fink J, et al. Fill volume, humidification and heat effects on aerosol delivery and fugitive emissions during noninvasive ventilation. J Drug Deliv Sci Technol 2017;39:372-8. doi: 10.1016/j. jddst.2017.04.026.

12. Edwards DA, Man JC, Brand P, et al. Inhaling to mitigate exhaled bioaerosols. Proc Natl Acad Sci U S A 2004;101:17383-8. doi: 10.1073/ pnas.0408159101.

13. Ari A. Promoting safe and effective use of aerosol devices in COVID-19: risks and suggestions for viral transmission. Expert Opin Drug Deliv 2020;17:1509-13. doi: 10.1080/17425247.2020.1811225.

14. Ari A, Harwood RJ, Sheard MM, Fink JB. An in vitro evaluation of aerosol delivery through tracheostomy and endotracheal tubes using different interfaces. Respir Care 2012;57:1066-70.

15. Wittgen BP, Kunst PW, Perkins WR, Lee JK, Postmus PE. Assessing a system to capture stray aerosol during inhalation of nebulized liposomal cisplatin. J Aerosol Med 2006;19:385-91. doi: 10.1089/jam. 2006.19.385. 
16. Ari A, Fink J, Harwood R, Pilbeam S. Secondhand aerosol exposure during mechanical ventilation with and without expiratory filters: an in-vitro study. Indian J Respir Care 2016;5:677-82.

17. Piccuito CM, Hess DR. Albuterol delivery via tracheostomy tube. Respir Care 2005;50:1071-6.

18. Ari A, Fink JB. Inhalation therapy in patients with tracheostomy: a guide to clinicians. Expert Rev Respir Med 2017;11:201-8. doi: 10.1080/ 17476348.2017.1289843.

19. Chang D, Xu H, Rebaza A, Sharma L, Dela Cruz C. Protecting healthcare workers from subclinical coronavirus infection. Lancet Respir Med 2020;8:e13. doi: 10.1016/S2213-2600(20)30066-7.
20. Fennelly M, Keane J, Dolan L, et al. Containment of procedure-associated aerosols by an extractor tent: effect on nebulised drug particle dispersal. J Hosp Infect 2021. doi: 10.1016/j.jhin.2021.01.009.

21. Phu HT, Park Y, Andrews AJ, et al. Design and evaluation of a portable negative pressure hood with HEPA filtration to protect health care workers treating patients with transmissible respiratory infections. Am J Infect Control 2020;48:1237-43. doi: 10.1016/j.ajic.2020.06.203.

22. Christopherson DA, Yao WC, Lu M, Vijayakumar R, Sedaghat AR. High-efficiency particulate air filters in the era of COVID-19: function and efficacy. Otolaryngol Head Neck Surg 2020;163:1153-5. doi: $10.1177 / 0194599820941838$. 